Journal of Agricultural Sciences
(Tarim Bilimleri Dergisi)

\title{
In vitro Regeneration Studies of Vuralia turcica Using Unpollinated Ovaries
}

Dilek TEKDAL

${ }^{a_{D e p a r t m e n t}}$ of Biotechnology, Faculty of Science and Letters, Mersin University, Yenişehir, Mersin, TURKEY

\section{ARTICLE INFO}

Research Article

Corresponding Author: Dilek TEKDAL, Turkey, E-mail: dilektekdal@mersin.edu.tr

Received: 10 August 2020 / Revised: 2 January 2020 / Accepted: 3 January 2020 / Online: 20 January 2022

\section{ABSTRACT}

Vuralia turcica is an endemic plant species with a polycarpellary gynoecium and has the ability to survive in salt stress. However, the maintenance of this species is currently challenging because of climatic changes in the plant's habitat, intensive agricultural purposes, grazing, and the like. Gynogenesis is a promising method for micropropagation and a useful technic for genetic engineering. The objective of this study was to analyze the gynogenesis of $V$. turcica. The experiments described here were implemented during the flowering time of $V$. turcica (spring) using unpollinated ovaries. Modified MS and B5 induction media and different plant growth regulators (BAP, $\mathrm{GA}_{3}, 2,4-\mathrm{D}$, and $\mathrm{KIN}$ ) were compared. The comparison of both media (MS and B5) showed that MS medium supplemented with 2,4-D and KIN was the best medium for in vitro unfertilized ovary culture and gave the best result of regenerated plants per 30 ovaries, and $92 \%$ callus was obtained. Only the control groups showed very low scores or no plants. From plant regeneration and subcultures, a total of 60 plants were produced, all green. These results are of interest to the in vitro conservation of endangered plant species like V. turcica.

Keywords: B5, legumes, MS, pure lines, ovary culture

(C) Ankara University, Faculty of Agriculture

\section{Introduction}

Plant tissue culture techniques are of the most important for the study and production of plants. The two most essential factors mainly affecting the track of study are the origin of the explant and culture medium. The literature of plant tissue culture may not apply to all results of a study because of differences in age, cell origin, and growth rate, as they may be associated with characteristics of a line (Gamborg et al. 1976; Bednarek \& Orlowska 2020). Also, haploidization as a kind of plant tissue culture is particularly important for producing pure lines. Anther and pollen (Androgenesis), as well as unfertilized ovary and ovule culture (Gynogenesis), allows the study of haploid plants (Sibi et al. 2001; Hazarika \& Chaturvedi 2013). Gynogenesis is the regeneration of plants from unfertilized cells of the female gametophyte. Explant sources for in vitro haploid plant production include blooming flowers, unpollinated ovaries, and ovules. Ovules attached to the placenta may respond more efficiently than their isolated counterparts. Induced haploids are mostly originated from the unfertilized egg cell (Bhojwani \& Razdan 1996).

Ovary culture has many applications, including embryo development, fruit development, physiology, the influence of phytohormones on the formation of parthenogenetic fruits, and the role of floral organs on fruit development, the stimulus of pollination in apomictic plants. Ovary culture may also be used in the production of hybrids, as it may overcome the problems such as the inability of pollen germination on stigma, insufficient development of pollen tube, and immature flower abscission. It is also used in inducing polyembryony, which results in many shoots (Van Tuyl et al. 1991).

Vuralia turcica (Tan et al. 1983), Uysal et al. (2014) is a rhizomatous plant species endemic to the region of Eber and Aksehir lakes in Turkey, belonging to the Fabaceae family, locally named as "Piyan." It has the significant property of usually having 3 (2 or 4 also being possible) ovaries within a flower bud, which makes the V. turcica unique in the Fabaceae family (Vural 2009) (Figure 1). Naturally, it only has two main subpopulations, which are found at protected properties and is under the danger of extinction due to the conversion of its habitat into agricultural fields, the intervention of nearby wetlands, and the change of suitable microclimate (Vural 2009). For clonal propagation, somatic cells are beneficial and reused mostly for the initiation of in vitro embryogenesis. In the case of the unfertilized ovule or ovary culture, embryogenesis occurs in the embryo sac cells or the somatic cells, or both (Reiser \& Fischer 1993).

In the present study, V. turcica was grown from unfertilized ovary explants, which were taken from Nezahat Gökyiğit Botanical Garden (NGBG) of Istanbul in Turkey. It is known from previous studies that micropropagation of $V$. turcica using its diploid explants such as rhizome, leaf, and epicotyl has already been conducted (Cenkci et al. 2009; Karadag et al. 2013). However, plant propagation using unfertilized ovary explants of $V$. turcica is the first attempt in this study. In the present study, the effects of culture conditions on cultured unfertilized ovaries of $V$. turcica were investigated. 


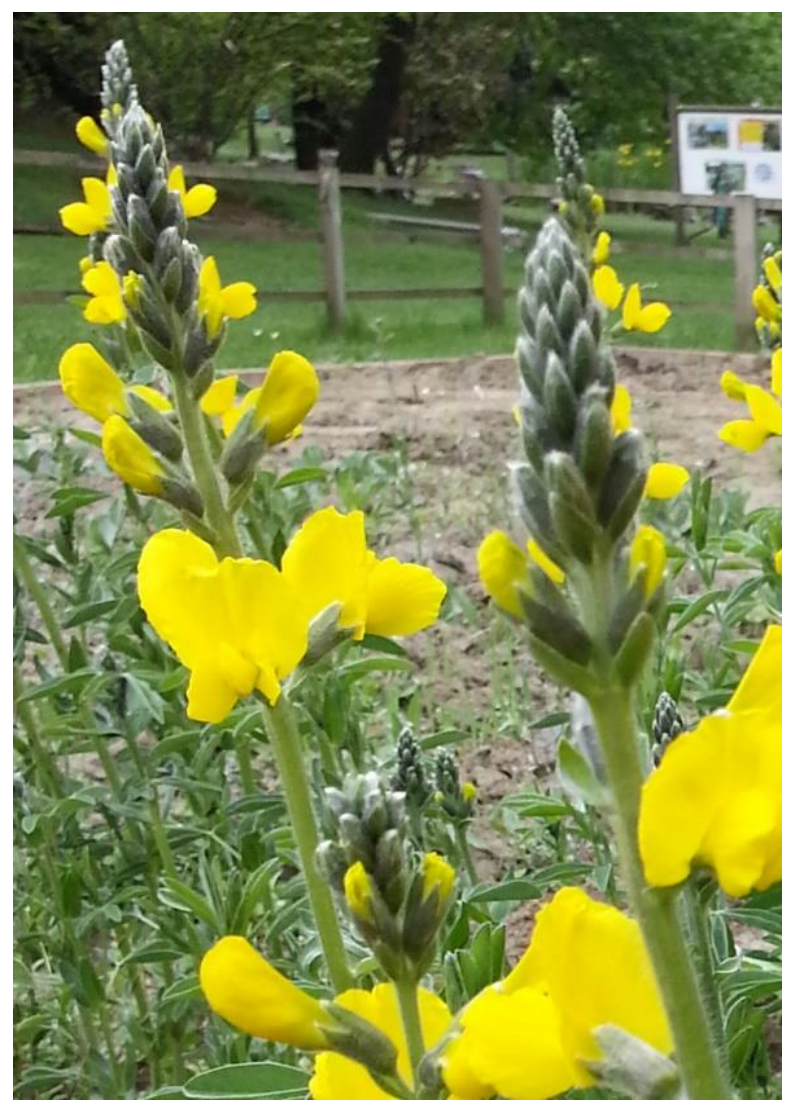

Figure 1- Flower and bud structure of V. turcica

\section{Material and Methods}

\subsection{Preparation of media}

Murashige and Skoog (MS) (1962) (Caisson Labs, USA), and Gamborg's B5 (B5) (1976) (Caisson Labs, USA) were used as primary media and different plant growth regulators, and concentrations as $0.5 \mathrm{mg} \mathrm{L}^{-1}$ Kinetin (KIN; Sigma-Aldrich, USA) + 0.5 $\mathrm{mg} \mathrm{L}^{-1}$ 2,4-Dichlorophenoxyacetic Acid (2,4-D; Sigma-Aldrich, USA) (Srivastava et al. 2009), $1 \mathrm{mg} \mathrm{L}^{-1}$ 6-Benzylaminopurine (BAP; Sigma-Aldrich, USA) + $0.1 \mathrm{mg} \mathrm{L}^{-1} \alpha$-Naphthaleneacetic Acid (NAA; Sigma-Aldrich, USA) (Chand \& Basu 1998) and 1 $\mathrm{mg} \mathrm{L}^{-1}$ 6-Benzylaminopurine $+0.2 \mathrm{mg} \mathrm{L}^{-1}$ Gibberellic Acid $\left(\mathrm{GA}_{3}\right.$; Sigma-Aldrich, USA) (Keller 1990) were tested with control (PGR-free) group for both media. Sucrose and agar in both media were added as $3 \%$ and $0.7 \%$, respectively. The $\mathrm{pH}$ of the media was adjusted to 5.7-5.8. Following autoclave at $121{ }^{\circ} \mathrm{C}(1 \mathrm{~atm}$ for $30 \mathrm{~min})$, the media poured sterilized plastic Petri dishes $(15 \mathrm{x}$ $60 \mathrm{~mm})$.

\subsection{Ovary culture}

The stock plants (V. turcica) were cultivated in a field located in NGBG under controlled conditions. The flower buds were harvested from the field at anthesis and subjected to sterilization with $10 \%$ bleach $\left(10 \%\right.$ brand bleach, $90 \% \mathrm{dH}_{2} \mathrm{O}$, and $1-2 \mathrm{drops}$ Tween 20) for 10 minutes and later on immersed in $70 \%$ ethanol for 5 minutes (adding fresh ethanol three times). Flower buds were rinsed three times with distilled water. Flower buds' gynoecium (ovarium) was picked up with tweezers by cutting flower petals and anthers. Two or three gynaecia (ovary) were collected per flower. The gynoecia were excised from the style part to separate ovary to be used as in the experiments. Six ovaries were placed on each Petri dish with a culture medium. Thirty ovaries were cultured for each experiment. Each experiment was conducted with five replicates.

\subsection{Culturing stage}

The Petri dishes were placed in a growth chamber at $26^{\circ} \mathrm{C}$ and $70 \%$ relative humidity, and $16 / 8 \mathrm{~h}$ light/dark photoperiod hours (light intensity is 8000 lux). The cultures were observed and photographed every second day. Morphogenetic responses were observed after a month of culture. Calli were detected within a month from the surface of ovary explants. The color of the calli varies from white to green; their surface showed structures such as the formation of shoots, and the calli were mostly regenerative. For plant regeneration, somatic embryos were transferred to a fresh MS medium without PGR, which was reported as a differentiation medium for $V$. turcica embryos. 


\subsection{Observations}

The data were compiled according to the response of cultured ovaries on MS and B5 media supplemented with different concentrations and combinations of hormones given in Table 1. The percentage responses were provided using total cultured ovaries and on responding ovaries. For each explant, regeneration percentages were determined by [(the number of regenerated plants $\div$ number of cultivated explants) x 100] equation.

Table 1- Methods of embryo induction by the culture of unpollinated ovaries

\begin{tabular}{|c|c|c|c|c|}
\hline Culture media $\left(\mathrm{mg} \mathrm{L}^{-1}\right)$ & References & Mode of inoculation & \multicolumn{2}{|c|}{ Type of induction medium } \\
\hline & & & $M S$ & $B 5$ \\
\hline & & & \multicolumn{2}{|c|}{ Total number of cultured ovaries } \\
\hline Control (PGR-free) & - & Ovary culture & 30 & 30 \\
\hline $0.5 \mathrm{KIN}+0.52,4-\mathrm{D}$ & Srivastava et al. (2009) & Ovary culture & 30 & 30 \\
\hline $1 \mathrm{BAP}+0.1 \mathrm{NAA}$ & Chand \& Basu (1998) & Ovary culture & 30 & 30 \\
\hline $1 \mathrm{BAP}+0.2 \mathrm{GA}_{3}$ & Keller (1990) & Ovary culture & 30 & 30 \\
\hline
\end{tabular}

Abbreviations and legend: 2,4-D (2,4-dichlorophenoxyacetic acid); NAA (naphthalene acetic acid); KIN (kinetin); GA 3 (gibberellic acid); BAP (6-benzyl amino purine); MS (Murashige-Skoog medium); B5 (Gamborg medium); PGR (plant growth regulator). Induction media were based on modified Murashige and Skoog (1960) for MS and Gamborg et al. (1976) B5.

\section{Results and Discussion}

Unfertilized ovaries of $V$. turcica have been cultured in vitro to obtain whole plants from the embryogenic cells.

Callus formation was observed from ovary samples of $V$. turcica in both media (MS and B5) (Table 2). In control groups cultured in the medium without PGR, neither callus nor embryos were formed. In both MS and B5 supplemented with KIN and 2,4-D, non-embryogenic calli were obtained with a high percentage (Table 2). The most efficient culture media for callus induction (92\%) was recorded as MS supplemented with 2,4-D (0.5 mg L-1) and KIN $\left(0.5 \mathrm{mg} \mathrm{L}^{-1}\right)$ (Table 2). Also, the responding embryos values were higher in MS medium supplemented with KIN $\left(0.5 \mathrm{mg} \mathrm{L}^{-1}\right)$ and 2,4-D $\left(0.5 \mathrm{mg} \mathrm{L}^{-1}\right)(58 \%)$ than that of B5 medium (21\%), which was relatively low (Table 2).

Table 2- Effects of the plant growth regulators on the production of somatic embryos in cultured unpollinated ovaries of $V$. turcica

\begin{tabular}{clccc}
\hline Medium no & \multicolumn{1}{c}{ Treatments } & $\begin{array}{c}\text { No. ovaries } \\
\text { cultured }\end{array}$ & $\begin{array}{c}\text { Percent ovaries } \\
\text { forming a callus }\end{array}$ & $\begin{array}{c}\text { Percent ovaries } \\
\text { forming embryos }\end{array}$ \\
\hline \multicolumn{7}{c}{ MS medium culture condition } & & & \\
\hline 1 & Control (PGR-free) & 30 & 0 & 0 \\
2 & $1 \mathrm{mg} \mathrm{L}^{-1} \mathrm{BAP}+0.2 \mathrm{mg} \mathrm{L}^{-1} \mathrm{GA}_{3}$ & 30 & 46 & 25 \\
3 & $1 \mathrm{mg} \mathrm{L}^{-1} \mathrm{BAP}+0.1 \mathrm{mg} \mathrm{L}^{-1} \mathrm{NAA}$ & 30 & 21 & 12 \\
4 & $0.5 \mathrm{mg} \mathrm{L}^{-1} \mathrm{KIN}+0.5 \mathrm{mg} \mathrm{L}^{-1} 2,4-\mathrm{D}$ & 30 & 92 & 58 \\
\hline \multicolumn{7}{c}{ B5 medium culture condition } & 30 & 0 & 0 \\
\hline 1 & Control (PGR-free) & 30 & 42 & 0 \\
2 & $1 \mathrm{mg} \mathrm{L}^{-1} \mathrm{BAP}+0.2 \mathrm{mg} \mathrm{L}^{-1} \mathrm{GA}$ & 30 & 18 & 10 \\
3 & $1 \mathrm{mg} \mathrm{L}^{-1} \mathrm{BAP}+0.1 \mathrm{mg} \mathrm{L}^{-1} \mathrm{NAA}$ & 30 & 83 & 21 \\
\hline
\end{tabular}

Legend: The percentages of callus or embryos per ovary were rounded to the nearest whole number.

There have been many reports on somatic embryogenesis from cultured unpollinated ovaries of many species, Psoralea corylifolia Linn. (Chand \& Sahrawat 2007), Azadirachta indica (Srivastava et al. 2009), Amorphophallus konjac (Zhao et al. 2012). However, few reports on in vitro embryogenesis in Vuralia turcica has been reported from leaves, stems (Tekdal \& Cetiner 2014a), and mature embryos (Tekdal \& Cetiner 2014b). In the present study, the effects of culture conditions on the development of somatic embryos from cultured unpollinated ovaries of $V$. turcica were investigated for the first time, according to a literature review. At 15 days in culture, the primary callus formed in ovaries cultured in the medium supplemented with 0.5 $\mathrm{mg} \mathrm{L}^{-1} \mathrm{KIN}$ and $0.5 \mathrm{mg} \mathrm{L}^{-1}$ 2,4-D (Figure 2). Two types of callus, a brownish and friable type in the MS medium and a white greenish and compact type in the B5 medium, were observed (Figures 3 and 4). Callus formation was higher (92\%) than all treatments. Somatic embryo formation was observed in MS medium supplemented with KIN and 2,4-D with a high frequency of $58 \%$ (Table 1). 

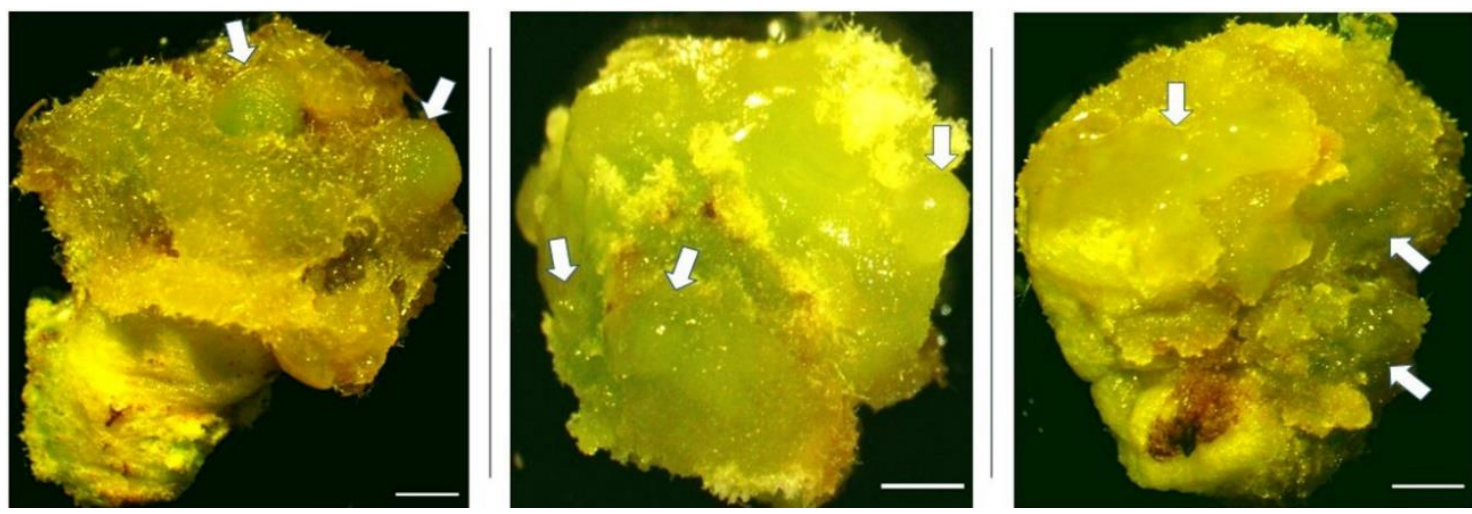

Figure 2- Embryogenic callus formation and somatic embryos (arrows) of $V$. turcica in the MS medium supplemented with 0.5 $\mathrm{mg} \mathrm{L}^{-1} \mathrm{KIN}$ and $0.5 \mathrm{mg} \mathrm{L}^{-1} 2,4-\mathrm{D}$; scale bar: $200 \mu \mathrm{m}$

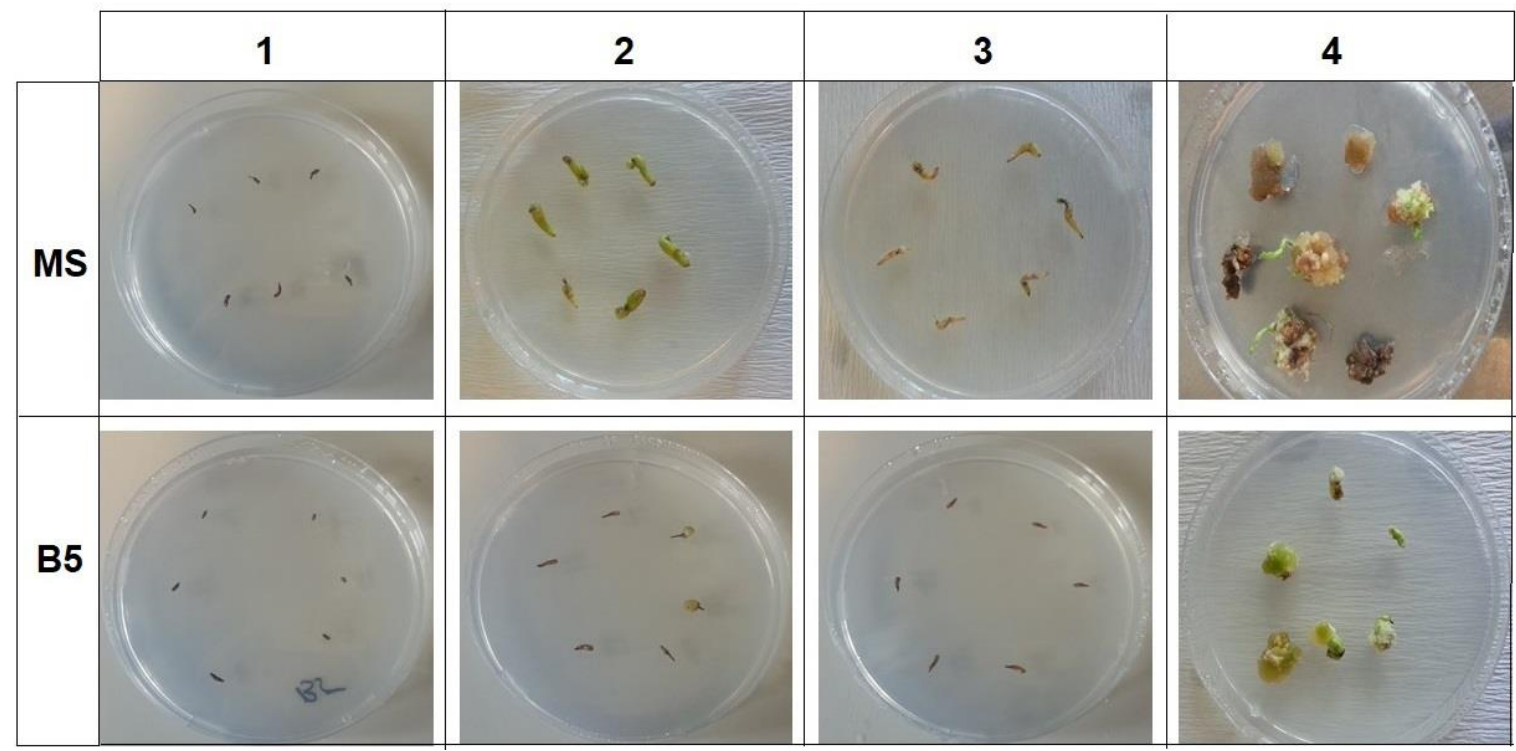

Figure 3- Calli were bursting through the ovaries of $V$. turcica after a month of in vitro culture (1-4 describes the medium no given in Table 2)

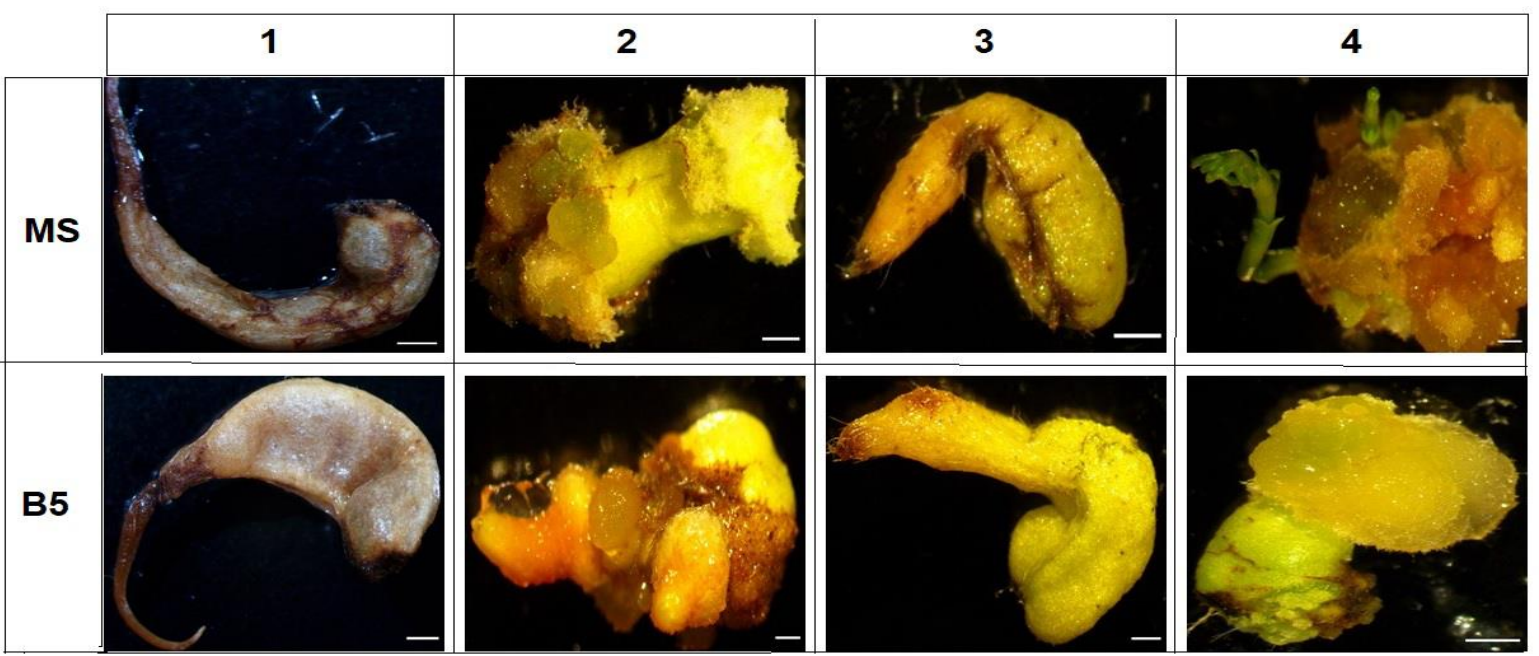

Figure 4- Regeneration of buds and callus from the ovary on MS and B5 media (1-4 describes the medium no given in Table 2) (Scale bar: $80 \mu \mathrm{m})$

Callus induction and somatic embryogenesis from various explant sources can be affected by plant growth regulators, salts, and organic substances in the culture medium. The nitrate: ammonium $\left(\mathrm{NO}_{3}{ }^{-} / \mathrm{NH}_{4}{ }^{+}\right)$rate and vitamin composition are the most prominent differences between MS and B5 media (Saad \& Elshahed 2012) used in this study. A previous study of Linum 
usitatissimum L. showed that callus formation was triggered when the rate of nitrate: ammonium increased. The reduction of the rate of nitrate: ammonium increased somatic embryogenesis and showed the best result of embryo development (Cunha \& Fernandes-Ferreira 1999). In V. turcica, it was observed that callus growth was higher in the MS medium when compared to the B5 medium (Table 2). It could be possible due to a high rate of nitrate: ammonium in the MS medium.

The embryogenic calli (Figure 2) were transferred to a PGR free medium, and after transferring, the embryos were directly transformed into plantlets (Figure 5). After two months on the medium, explants developed into plantlets.
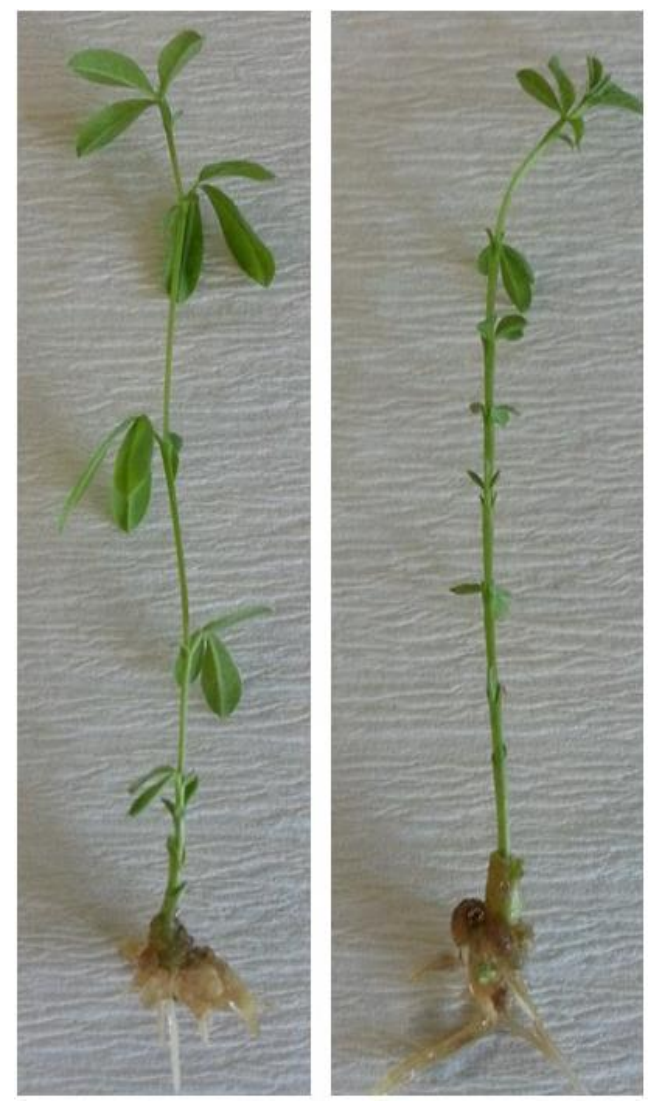

Figure 5- Plantlets regenerated from unpollinated ovary culture of $V$. turcica, at the left, regenerated plant from callus formed on MS medium with 2,4-D $\left(0.5 \mathrm{mg} \mathrm{L}^{-1}\right)$ and $\mathrm{KIN}\left(0.5 \mathrm{mg} \mathrm{L}^{-1}\right)$, and at the right of a plantlet from the callus formed on B5 medium with 2,4-D $\left(0.5 \mathrm{mg} \mathrm{L}^{-1}\right)$ and $\mathrm{KN}\left(0.5 \mathrm{mg} \mathrm{L}^{-1}\right)$

In the present study, plant regeneration was obtained from somatic embryos from ovary tissues of $V$. turcica successfully. This is the first report of somatic embryogenesis from unfertilized ovaries of $V$. turcica.

\section{Conclusions}

$V$. turcica is the only known species of the genus Vuralia and is currently in danger of extinction. For these reasons, studies on the conservation of this unusual species are of great interest. The regeneration of $V$. turcica in vitro conditions depends critically on choosing sufficient explant and culture conditions. In this study, it can be concluded that the most successful medium for plant regeneration in ovary culture was MS + KIN $\left(0.5 \mathrm{mg} \mathrm{L}^{-1}\right)+2,4-\mathrm{D}\left(0.5 \mathrm{mg} \mathrm{L}^{-1}\right)$. The in vitro culture of unfertilized ovaries of $V$. turcica described in this study can be applied as an alternative way to obtain somatic plants with the same characteristics as the maternal cultivar in a short time. The development of this technique will be significant not only in the conservation of this endangered plant species but also in the multiplication of this species in order to use for many agronomical purposes such as breeding and obtaining valuable compounds. Besides, for use in transformation/regeneration investigations and in vitro manipulation of $V$. turcica, the described regeneration method can be adapted.

\section{Acknowledgments}

The author would like to thank Nezahat Gökyiğit Botanical Garden, Istanbul, Turkey, for providing research material and their support. 


\section{References}

Bednarek P T \& Orlowska R (2020). Plant tissue culture environment as a switch-key of (epi)genetic changes. Plant Cell, Tissue and Organ Culture 140:245-257. doi: 10.1007/s11240-019-01724-1

BhojwaniS S \& Razdan M K (1996). Plant Tissue Culture : Theory and Practice, a Revised Edition. Elsevier

Cenkci S, Temel M, Kargioğlu M \& Dayan S (2009). Propagation of endangered Thermopsis turcica Kit Tan, Vural \& Küçüködük using conventional and in vitro techniques. Turkish Journal of Biology 33: 327-33. doi: 10.3906/biy-0811-1

Chand S \& Basu P (1998). Embryogenesis and plant regeneration from callus cultures derived from unpollinated ovaries of Hyoscyamus muticus L. Plant Cell Reports 17(4): 302-305. doi: 10.1007/s002990050397

Chand S \& Sahrawat A K (2007). Embryogenesis and plant regeneration from unpollinated ovary culture of Psoralea corylifolia. Biologia Plantarum 51(2): 223-228. doi: 10.1007/s10535-007-0045-5

Cunha A \& Fernandes-Ferreira M (1999). Influence of medium parameters on somatic embryogenesis from hypocotyl explants of flax (Linum usitatissimum L.): effect of carbon source, total inorganic nitrogen and balance between ionic forms and interaction between calcium and zeatin. Journal of Plant Physiology 155: 591-597. doi: 10.1016/S0176-1617(99)80059-5

Gamborg O L, Murashige T, Thorpe T A \& Vasil I K (1976). Plant tissue culture media. In Vitro Cellular and Developmental Biology-Plant 12: $473-478$

Hazarika R R \& Chaturvedi R (2013). Establishment of dedifferentiated callus of haploid origin from unfertilized ovaries of tea (Camellia Sinensis (L.) O. Kuntze) as a potential source of total phenolics and antioxidant activity. In Vitro Cellular and Developmental Biology Plant 49(1): 60-69. doi: 10.1007/s11627-013-9490-3

Karadag B N, Yildirim E C \& Tekdal D (2013). The comparison of plant regeneration between Jerusalem artichoke and purple potato cultured on MS media with different concentrations and combinations of plant growth regulators. International Journal of Bioscience, Biochemistry and Bioinformatics 3(2): 120-124. doi: 10.7763/IJBBB.2013.V3.178

Keller J (1990). Culture of unpollinated ovules, ovaries, and flower buds in some species of the genus Allium and haploid induction via gynogenesis in onion (Allium cepa L.). Euphytica 47(3): 241-247. doi: 10.1007/BF00024247

Murashige T \& Skoog F (1962). A revised medium for rapid growth and bioassays with tobacco tissue cultures. Physiologia Plantarum 15: 473-497. doi: 10.1111/j.1399-3054.1962.tb08052.x

Reiser L \& Fischer R L (1993). The ovule and the embryo sac. Plant Cell 5: 1291-1301. doi: 10.1105/tpc.5.10.1291

Saad A I M \& Elshahed A M (2012). Plant tissue culture media. In: Leva A \& Rinaldi L (Eds.), Recent Advances in Plant in vitro Culture, Intech, UK, pp. 29-40

Sibi M L, Kobaissi A \& Shekafandeh A (2001). Green haploid plants from unpollinated ovary culture in tetraploid wheat (Triticum durum Defs.). Euphytica 122(2): 351-59. doi: 10.1023/A:1012991325228

Srivastava P, Singh M, Mathur P \& Chaturverdi R (2009). In vitro organogenesis and plant regeneration from unpollinated ovary cultures of Azadirachta indica. Biologia Plantarum 53(2): 360-364. doi: 10.1007/s10535-009-0067-2

Tan K, Vural M \& Küçüködük M (1983). An unusual new Thermopsis from Turkey. Notes Royal Botanical Garden Edinburgh 40(3): 515518

Tekdal D \& Cetiner S (2014a). In vitro plant regeneration derived from leaf and stem explants of endemic Thermopsis turcica. Biologia 69: 863-869. doi: 10.2478/s11756-014-0383-7

Tekdal D \& Cetiner S (2014b). In-ovule embryo culture of Thermopsis turcica. Journal of Animal and Plant Sciences 26(6): 1673-1679

Uysal T, Ertuğrul K, \& Bozkurt M (2014). A new genus segregated from Thermopsis (Fabaceae: Papilionoideae): Vuralia. Plant Systematics and Evolution 300: 1627-1637. doi: 10.1007/s00606-014-0988-x

Van Tuyl J M, Van Diën M P, Van Creij M G M, Van Kleinwee T C M, Franken J \& Bino R J (1991). Application of in vitro pollination, ovary culture, ovule culture and embryo rescue for overcoming incongruity barriers in interspecific Lilium crosses. Plant Science 74(1): 115-126. doi: 10.1016/0168-9452(91)90262-7

Vural M (2009). Piyan (Thermopsis turcica). Bağbahçe 25: 14-16. (In Turkish)

Zhao L, Wu J, Diao Y \& Hu Z (2012). Embryogenesis and plant regeneration from unpollinated ovaries of Amorphophallus konjac. African Journal of Biotechnology 11(70): 13472-13476. doi: 10.5897/AJB12.1827

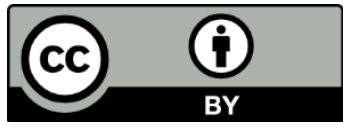

(C) 2022 by the author(s). Published by Ankara University, Faculty of Agriculture, Ankara, Turkey. This is an Open Access article distributed under the terms and conditions of the Creative Commons Attribution (CC BY) license (http://creativecommons.org/licenses/by/4.0/), which permits unrestricted use, distribution, and reproduction in any medium, provided the original work is properly cited. 